ГЕМОБЛОК, КАК СРЕДСТВО УСКОРЕНИЯ РЕАБИЛИТАЦИИ ПОСЛЕ ТОНЗИЛЛЭКТОМИИ.

DOI: $10.31618 / \mathrm{ESU} .2413-9335.2020 .3 .71 .591$

В.Г.Лейзерман., (1) Н.Э.Артемова, (2) М.Г.Лейзерман

((1) ФГБОУ ВО ОРГМУ МЗ РФ

Оренбургский государственный медицинский Университет

(2) ГБУЗ ДЗМ

Московская городская клиническая больница №29 им.Н.Э.Баумана)

\title{
HEMOBLOCK ES AN ACCELERATION CURE FOR REHABILITATION AFTER TONZYLLECTOMY.
}

\author{
Leyzerman V.G., Artemova N.E., Leyzerman M.G. \\ Orenburg State Medical University OrSMU, \\ Moscow City Clinical Hospital №29.
}

\section{PЕЗЮМЕ}

Обсуждаются проблемы реабилитации после операции с использованием препарата Гемоблок. Изучена группа больных (165 человек), у которой применяли Гемоблок и контрольная группа (160) больных. Получены и обсуждены результаты исследования, согласно которым Гемоблок позволяет избежать осложнений операции и ускорить процесс реабилитации пациентов.

\section{SUMMARY}

The problems of after surgery rehabilitation using the Hemoblock were discussed. A group of patients (165 people) was studied, a group of patients who used Hemoblock and a control group (160) of patients were used. There are results of the study revealed that the Hemoblock avoids surgery and accelerates the rehabilitation process.

Ключевые слова: гемоблок, тонзиллэктомия, реабилитация.

Key words: hemoblock, tonsillectomy, rehabilitation.

Учитывая высокую распространенность операций - тонзилэктомий - в отделениях уха, горла и носа, а также длительный период восстановления трудоспособности, вопросы оптимизации операций и послеоперационной реабилитации остаются актуальными.

Проблема хронического тонзиллита чрезвычайно важна в связи с высокой распространенностью (от 15 до 20\% населения страдает различными формами этого заболевания [1]), во-многом неразрешенностью, а также частыми и серьезными осложнениями в виде ревматических, почечных и иных системных болезней [2].

В тех случаях, когда пациент переносит более 2 ангин в году, госпитализацию и операцию по поводу паратонзиллярного абсцесса, а обследование выявляет положительные ревмопробы, симптомы гломерулонефрита, нарушения проводимости миокарда, больным предлагается тонзиллэктомия [2]. Эта операция, несмотря на длительную историю и появление современной аппаратуры и инструментов, всегда связана с кровоточивостью тканей глотки, которая возникает в связи с обильным кровоснабжением, возможными нарушениями системы свертывания крови и другими причинами.

Предложено большое количество медикаментозных средств и инструментов для того, чтобы снизить степень кровоточивости раны как в процессе операции, так и в послеоперационном периоде, однако все они не гарантируют от возникновения осложнений, поэтому поиск новых средств и методов хирургического воздействия продолжается.
Одним из таких средств, появившихся в последние годы является ГЕМОБЛОК, представляющий $1 \%$ водный раствор неполной серебряной соли полиакриловой кислоты, содержащий наночастицы серебра. Состав гемоблока оказывает гемостатическое и бактерицидное действие, ускоряет тромбоцитарный гемостаз за счет повышения вязкости крови и агрегации тромбоцитов [3\} .

На раневой поверхности препарат образует матричную структуру на основе полиакрилатной матрицы. Белки плазмы (альбумин, фибриноген) образуют соединение с ионами серебра и создают тонкую пленку до 1 микрона толщиной, которая появляется уже через несколько секунд после воздействия. Важнейшим компонентом создания однородной пленки является одновременность роста белковой структуры независимо от морфологии и состава повреждающейся ткани. Ионы серебра в пленке обеспечивает дополнительную асептическую среду, способствующую регенерации биоткани.

Исследования воздействия гемоблока на раневые поверхности проводились в различных специальностях (хирургии, гинекологии, проктологии), однако нам не удалось найти публикаций, посвященных применению при операциях у больных хроническим тонзиллитом. В связи с этим мы попытались оценить эффективность использования Гемоблока у пациентов ЛОР отделения в процессе тонзиллэктомии и в послеоперационном периоде. Препарат применяли у 165 пациентов в возрасте от 18 до 47 лет. Из них было 74 женщины и 91 мужчина. Все они были госпитализированы с 
диагнозом Хронический тонзиллит, токсикоаллергическая форма 2 ст., при этом 32 пациента имели в анамнезе от 1 до 3 паратонзиллярных абсцессов. Тонзиллэктомия выполнялась как под местной анестезией (112), так и под общим обезболиванием (53 человека). При операции были использованы как механические, так и высокотехнологичные инструменты (радиочастотный аппарат «Curis» -Германия). Известно, что радиочастотное воздействие в режиме коагуляции обладает хорошим кровоостанавливающим свойством, которое применяется нами на протяжении более 10 лет.

В процессе операции Гемоблоком пропитывали марлевые тампоны, которые прижимали к раневой поверхности на 1 - 2 минуты, после чего выполняли последующие этапы вмешательства. За время тонзиллэктомии тампоны с Гемоблоком использовали 2 - 3 раза в различные стадии вмешательства.

Мы сравнили послеоперационный период у обследуемых пациентов (165 человек - 1 группа) и теми, кто был ранее оперирован без применения гемоблока (160 человек - 2 контрольная группа). Оказалось, что в первой группе ранние послеоперационные кровотечения (в первые сутки) отмечены лишь у одного пациента, тогда как у больных второй группы их было 3. Длительность пребывания в стационаре определялась общим состоянием больного, выраженностью болевого синдрома, температурной реакцией, картиной заживления в тонзиллярных нишах. Мы отметили, что у пациентов 1 группы средняя продолжительность госпитализации составили 3,2 койко-дня, тогда как во второй группе она оказалась 4,1 койко-дня.

Далее мы попробовали оценить длительность реабилитации после выписки из стационара. Для этого нам удалось побеседовать по телефону с пациентами обеих групп. Полученные данные свидетельствовали о том, что больные, перенесшие тонзиллэктомию полностью восстановились и смогли приступить к работе или учебе в среднем через 5,3 дней домашнего режима, тогда как пациенты 2 группы отметили полную трудоспособность через 5,8 дней.

Мы связали эти данные во-первых, со снижением степени кровоточивости раны в процессе операции и послеоперационного периода, поскольку рана без кровяных сгустков лучше очищается и раньше гранулирует. Во-вторых, образование бактерицидной пленки на раневой поверхности улучшает процесс регенерации и сокращает сроки заживления. И, наконец, в третьих, наложение кровоостанавливающих зажимов на сосуды и поверхность тканей вызывает ишемию в этой зоне, провоцирует локальные некротические изменения и, тем самым, удлиняет процесс очищения и заживления раневой поверхности.

Таким образом, мы выяснили, что использование препарата ГЕМОБЛОК позволяет не только оптимизировать процесс тонзиллэктомии, но и предупредить возможные осложнения, ускорить заживление тонзиллярной ниши, сократить сроки трудовой и социальной реабилитации.

\section{Литература:}

1.Крюков А.И., Аксенова АВ., Захарова А.Ф., Чумаков П.Л., Жук Л.Г. Особенности эпидемиологии хронического тонзиллита в современных условиях оказания специализированной ЛОР-помощи. \І Вестник отриноларингологии, 2013, №3, с.4-7.

2.Косяков С.Я., Анготоева И.Б., Мулдашева А.А. Противоречивость современных представлений о проблеме хронического тонзиллита. \\ Медицинский совет, 2015, №3, с.3740.

3.Плоткин А.В., Покровский Е.Ж., Воронова Г.В., Менглет К.А. Оценка эффектиности гемостатического действия препарата «Гемоблок» при полостных и эндоскопических вмешательствах. \لВестник современной клинической медицины, 2015, том 8, вып.1, с.56-61. 